\title{
Una memoria sexuada del cosmos: El marco heteropatriarcal de la cámara telescópica de Patricio Guzmán en Nostalgia de la luz (2010)
}

\author{
Nagore Sedano Naveira \\ University of Puget Sound
} nsedanonaveira@pugetsound.edu

\begin{abstract}
In this article, I draw on Sara Ahmed's theorization of "queer phenomenology" to examine the re-orientation of memory discourses in Patricio Guzman's Nostalgia de la luz (2010).

In Nostalgia, the camera produces a metaleptic effect by meticulously framing, in a similar manner to that of a telescope, the background of the official historical narrative: the memory of the natural world. Guzmán's metaleptic camera teaches us an interconnected "memory of the cosmos." Yet this re-orientation of memory discourses is articulated from a family home that serves as a gendered orienting device. Following queer phenomenology,
\end{abstract}


I trace the ways in which the documentary's innovative treatment of memory is hindered by the heteropatriarchal orientation of the family home. I argue that, in Nostalgia, the memory of the heterosexual male subject is the one that is transmitted vertically within the heteropatriarchal family. In doing so, the documentary reproduces the familial and linear tropes that have dominated discourses of intergenerational memory transmission. Queer phenomenology warns us that Guzman's call to "vivir en el frágil tiempo presente” is not merely a question of having or lacking memory.

Memory is a matter of following, and returning, specific lines of orientation, at the expense of others.

Keywords: Memory Studies; Queer Studies; Gender Studies; Latin American Documentary Film; Film Studies; Phenomenology; Post-Dictatorial Chile; Politics of Historical Memory; Patricio Guzmán; Contemporary Chilean Social Documentary

\section{Resumen}

En el presente artículo, me valgo de la fenomenología queer de Sara Ahmed para examinar la re-orientación de los discursos de la memoria de Patricio Guzmán en Nostalgia de la luz (2010). En Nostalgia, la cámara produce un efecto metaléptico al poner minuciosamente el foco, de similar manera a un telescopio, en el telón de fondo de la narración histórica oficial: la memoria del mundo natural. Pero si bien la cámara metaléptica de Guzmán nos enseña a "tener memoria" del cosmos, esta re-orientación se efectúa desde una casa familiar, es decir, un dispositivo orientador sexuado. Propongo que el innovador trato de la memoria del filme queda limitado por la orientación heteropatriarcal que marca la casa familiar, lo cual relega al fuera de campo otros paradigmas de transmisión intergeneracional de la memoria. Argumento que en Nostalgia es la memoria encarnada del sujeto masculino heterosexual la que se trasmite verticalmente siguiendo las líneas de la familia heteronormativa. Una lectura del documental desde la fenomenología queer nos advierte que "vivir en el frágil tiempo presente" no es simplemente una cuestión de "tener memoria" o no, sino de qué orientaciones posibilitan esa memoria y de cuáles, a su vez, posibilita ésta. 
Palabras clave: Estudios de la memoria; Documental Latinoamericano; Estudios de cine; Fenomenología; Chile post-dictatorial; Política de la memoria; Patricio Guzmán; Documental social chileno contemporáneo; Estudios de género; Estudios queer

“Haciendo esta película, mirando hacia atrás, estas bolitas [canicas] también me recuerdan la inocencia de Chile cuando yo era niño. En esa época, cada uno de nosotros podía guardar en el fondo de sus bolsillos el universo entero."

- Patricio Guzmán

T ras casi cuarenta años de carrera cinematográfica, el conjunto de la obra documental del chileno Patricio Guzmán ha forjado, en palabras del crítico Patrick Blaine, un "archivo de memoria" de la historia contemporánea de su país natal. Pieza clave de esta reflexión cinematográfica sobre la memoria es su penúltimo documental Nostalgia de la luz (2010). En el filme, los crímenes contra la humanidad cometidos por el régimen de Augusto Pinochet se tornan en escenario para re-pensar el proyecto de memoria histórica chileno. El cineasta-narrador en primera persona, como se advierte en el epígrafe que remite a un fragmento de la escena final, se vuelca en la metalepsis ("haciendo esta película") para poner el foco en el backstage (la inocencia infantil como metáfora del Chile pre-dictatorial) de la memoria ("mirando hacia atrás"). La teatralidad de la narración histórica se acentúa con una panorámica lenta a un mini-escenario compuesto por un taburete repleto de canicas que, según la voz en off, representa cada planeta de la constelación de problemas de Chile. Esta cadena de metáforas de la naturaleza no es fortuita; expone la novedosa apuesta del director en reconceptualizar la memoria reciente de la nación como parte inseparable de la memoria de la tierra. Al igual que en una galaxia de canicas, cada elemento físico guarda una traza histórica que orienta e interconecta al individuo con la constelación temporal y espacial del presente político. Esta nueva dirección de la memoria está guiada por la 
corriente historiográfica de la Gran Historia (Big History), la cual aboga por difuminar las barreras que separan la historia natural de la humana.

En el presente artículo me valgo de la fenomenología queer feminista de Sarah Ahmed para examinar el potencial y las limitaciones de la re-orientación de los discursos de la memoria que plantea Nostalgia. Desarrollo una lectura crítica del dispositivo fílmico que sustenta esta maniobra: la metalepsis producida por el paralelismo entre la cámara y el telescopio. Propongo que la metalepsis desorienta al poner minuciosamente el foco, de similar manera a un telescopio, en el telón de fondo de la narración histórica oficial: el mundo natural y el doméstico. Pero el carácter meta-narrativo de la metalepsis también nos re-orienta. Este dispositivo fílmico nos muestra la fragilidad del presente al dirigir nuestra mirada hacia la traza histórica, la memoria, que albergan los objetos domésticos y el desierto de Atacama. Curiosamente lo que desmantela el novedoso tratamiento de Nostalgia del género documental es su falta de atención al género y la sexualidad. Defiendo que la obra, pese a romper el marco antropocéntrico e historicista del documental de la memoria histórica, reproduce el marco heteropatriarcal que históricamente ha guiado los discursos de memoria de la izquierda. El filme de Guzmán reinscribe el sujeto histórico tradicional de la nación capitalista. No sólo es el sujeto masculino heterosexual quien hace y escribe memoria histórica, sino que es su memoria encarnada la que se trasmite dentro de la familia heteronormativa. Nostalgia se suscribe a una visión heteropatriarcal de la operativa de la memoria que relega al fuera de campo la historia de la lucha política de todo aquel que no encaje con el sujeto histórico (masculino y heterosexual) tradicional.

\section{Nostalgia de la luz: Punto de llegada y partida}

Nostalgia es un film que esboza el Chile contemporáneo a través de una narrativa que cohesiona esferas aparentemente dispares como la astronomía, la arqueología o la búsqueda de los cadáveres de aquellos asesinados bajo la 
dictadura de Pinochet. Todos ellos comparten un espacio y tiempo común que se convierte en eje central narrativo: el desierto de Atacama. Por medio de entrevistas, el documental revela que desde este desierto, o como argumenta Guzmán "gran libro abierto de la memoria," los astrónomos miran al cielo con los telescopios más grandes del mundo, los arqueólogos indagan en su suelo para observar el paso del tiempo y los familiares de las víctimas de la dictadura excavan su tierra seca en busca de sus difuntos.

La obra es la pieza más novedosa de una carrera cinematográfica centrada en la historia contemporánea chilena y la primera de una trilogía en marcha. Al relacionar temáticamente esta obra con el resto del corpus documental de Guzmán, para Michael Chanan, “[Guzmán] emprende otro viaje hacia el espacio de amnesia que es la historia de Chile" ("Nostalgia” n.p.). Sin embargo, esta obra no se trata simplemente de "otro viaje" o un viaje más a una materia que el director ya venía trabajando desde La batalla de Chile con obras como Chile, la memoria obstinada (1997), El caso Pinochet (2001), Salvador Allende (2004) o Chile una galaxia de problemas (2010). Lo que tiene de especial esta nueva mirada a la memoria histórica es que se extiende al uso de la cámara y el cine, para teorizarlos como, en palabras de Julieta Vitullo, "artificio que posibilita metáforas y abre caminos para un viaje por el tiempo que se presenta como una máquina de indagación y sondeo (como el telescopio)" (181). El mensaje de Guzmán involucra no sólo a nivel instrumental, sino también a nivel conceptual a la cámara como herramienta que lo codifica, transmite y somete a estudio. Con ello, elabora una obra innovadora que repiensa la orientación espacio-temporal del documental social, difuminando las barreras que lo separan del género científico.

Este peregrinaje se suma, además, al giro subjetivo y el tinte autobiográfico del documental chileno contemporáneo. El documental lanza una mirada a la memoria colectiva vía la memoria individual. El director se inserta en la obra como narrador en primera persona que repasa el pasado y presente del país. 
En este sentido, Nostalgia es integrante de lo que Valeria Valenzuela identifica como género "híbrido." En "Yo te digo que el mundo es así: Giro performativo en el documental chileno contemporáneo" (2006), Valenzuela define el "género híbrido" como una categoría relativamente nueva del documental histórico chileno que se viene gestando desde los años noventa (12). Para Valenzuela, la interferencia del cineasta en el objeto filmado es una tendencia que manifiesta un nuevo acercamiento al documental chileno: se deja atrás su "función probatoria," para enfocarse en su performatividad. Este nuevo carácter subjetivo y auto-referente marca un giro de "la representación de lo real” a "lo real de la representación" que no aspira únicamente a la reconstrucción de la memoria, sino a subrayar la manera particular "en que cada uno recuerda, y a partir de esto, opta y construye su forma de entender el mundo" (18). Coincido con Valenzuela en afirmar que Guzmán, ya desde Chile, la memoria obstinada (1997), experimenta con derrocar las barreras del género con la inserción de su experiencia personal. Sin embargo, en Nostalgia, Guzmán novedosamente dirige esta experiencia personal hacia la memoria de la tierra.

Me apoyo en la fenomenología para examinar esta reformulación de la memoria por su énfasis en la experiencia de la percepción sensorial, intencionalidad y significación. En particular, me centro en el trabajo de Sarah Ahmed por su acercamiento interseccional a las diferentes variables identitarias (raza, género, sexualidad...) que configuran nuestra toma de conciencia. En "Orientations: Toward a Queer Phenomenology" (2006), Ahmed argumenta que el sujeto se constituye como tal por medio de orientaciones. Éstas se entienden como los puntos cero donde el mundo se despliega ante el sujeto, poniendo en su horizonte ciertos objetos y no otros (543). Esta serie de objetos inmediatos condicionarán nuestra relación con el mundo: "the objects that we direct our attention toward reveal the direction we have taken in life. If we face this way or that, then other orientations things, and indeed spaces, are relegated to the background; they are only ever co-perceived" (546-47). 
Para Ahmed, lo queer supone una política de desorientación que atenta contra lo socialmente aceptable. Al cuestionar la manera de estar en el mundo o la configuración espacial y temporal que impone la heteronormatividad en nuestros cuerpos, lo queer pone a nuestro alcance otro tipo de objetos. Pese a que Guzmán no comparte la preocupación interseccional de Ahmed, Nostalgia inserta en nuestro horizonte elementos y conexiones entre ellos que la narración histórica oficial obvia.

En otras palabras, la fenomenología permite examinar la desorientación que produce el documental en el espectador al resaltar en primer plano aquello que tradicionalmente ha quedado fuera del encuadre del documental sobre la memoria histórica de Chile: la memoria de la naturaleza. Guzmán lanza su mirada fenomenológica a la realidad física desde la "Gran Historia." Esta escuela, según explican Craig Benjamin, Esther Quaedackers y David Baker en The Routledge Companion to Big History (2018), retoma los presupuestos de la historiografía de la antigüedad clásica para abogar por una narrativa que unifique la historia del ser humano y la del mundo físico que habita (4). En una entrevista con Chris Darke para PBS, la propia reflexión de Guzmán acerca del filme hace eco de estos preceptos: "In Nostalgia there is, of course, an element of philosophical reflection on the relationship between human life and the life of the cosmos, on human memory and the memory of the stars, of infinity" (Guzmán en Darke). Es precisamente el acercamiento de la Gran Historia el que el cineasta desarrolla en sus dos obras posteriores, El botón de nácar (2015) y La cordillera de los sueños (2019), convirtiendo a Nostalgia de la luz en la primera pieza de una trilogía. En este corpus documental, el director se suscribe a la consiliencia que propone esta corriente historiográfica con el fin de, en palabras de David Christian, entender de manera holística nuestro mundo presente (16). ' Siguiendo esta metodología, Nostalgia desarrolla un análisis interdisciplinario (astronomía, historia, arqueología...) que liga el pasado reciente del ser humano con la historia del planeta y la del universo. 
La crítica no ha pasado por alto este giro al mundo natural, lo que para John Parham y Pippa Marland convierte a Nostalgia en eco-documental. ${ }^{2}$ El presente ensayo presta atención al cómo se construye fílmicamente este giro desde la perspectiva de la fenomenología. Esta ciencia, la fenomenología, ofrece un modo de investigación idóneo para esclarecer dos puntos interconectados: por un lado, cómo el tratamiento de Nostalgia de la recepción afectiva de la imagen en movimiento replantea formalmente el género documental; y por otro, la reorientación temporal y espacial de los discursos de la memoria que formula esta innovación estética. Recurro a la fenomenología, por lo tanto, como un marco teórico que permite analizar ambos: la mirada de Guzmán a la realidad física y la codificación de ésta fílmicamente con fines políticos. Con ello, mi objetivo no es analizar detalladamente la retórica ecologista del documental. En lugar de ello, busco esclarecer las limitaciones de esta re-orientación de los discursos de la memoria en lo que respecta al pasado dictatorial reciente de Chile. Los postulados de Ahmed son imprescindibles en este punto. A la hora de definir lo que constituye una desorientación queer que atente contra la heteronormatividad, en Queer Phenomenology: Orientations, objects, Others (2006), Ahmed insiste en que no toda desorientación implica una transgresión; "The form of politics that proceed from disorientation can be conservative, depending on the "aims" of their gestures, depending on how they seek to (re) ground themselves" (158). Lo que importa es el potencial de la nueva dirección planteada tras la desorientación y de ahí, la necesidad de ver Nostalgia desde la fenomenología queer para vislumbrar dónde y por qué quiebra su potencial transformador respecto a la política de memoria histórica de Chile. En las próximas páginas, propongo una lectura crítica del filme de Guzmán desde Ahmed con el fin de iluminar la visión tradicional de la memoria de la resistencia anti-Pinochet desde la cual Guzmán articula la "nueva” dirección del documental social. 


\section{Una mirada telescópica a la realidad física}

A través de la metalepsis, Guzmán codifica su proceso de toma de conciencia de la "memoria de la tierra" de manera que el espectador se vea forzado a repensar el propio suyo, es decir, a reorientarse en términos espaciales y temporales. Ya desde su propia apertura, Nostalgia hace uso de la metalepsis con la analogía entre la cámara y el telescopio para incitar a la audiencia a cuestionar su relación con el documental social. El filme comienza intercalando primeros planos y planos detalle de diversas piezas, tornos, ruedas o engranajes de un telescopio que, tal y como indica el sonido diegético, está a punto de ponerse en marcha. Después de un fundido a negro y dar paso al título, se vuelve a primeros planos del telescopio, pero haciendo inciso esta vez en su enfocador y ocular, como si el director quisiera incitar al espectador a mirar por éste. Seguido, con un contrapicado que imita la misma postura que ha adquirido el telescopio preparado ya para operar, la cúpula del observatorio se abre y da paso a una luz blanca procedente del exterior. La siguiente secuencia presenta imágenes de la superficie lunar. A continuación, desde el interior de una casa, un primer plano ligeramente contrapicado muestra una ventana y en ella, se reflejan las sombras de las hojas de árbol. Esta secuencia inicial marca una pauta para leer el resto del documental: las imágenes que Guzmán como documentalista registra con su cámara se presentan como si fueran imágenes que ha obtenido un astrónomo por medio del telescopio. Este paralelismo metafórico deshace las expectativas temáticas del documental sobre la memoria histórica, es decir, desorienta a la audiencia al sumarse a la consiliencia por la que aboga la Gran Historia.

Es en esta segunda escena donde se da comienzo a la narración de Guzmán, contextualizando la obra a través del "viejo telescopio alemán” de su infancia "que todavía funciona" en Santiago de Chile. Acompañado de la voz en off del narrador-director, la cámara realiza una secuencia lenta de primeros 
planos de los objetos domésticos: una silla, una mesa, las sombras de las hojas de árbol en el suelo, un sofá, una máquina de coser antigua Según explica la narración, estos instrumentos pertenecen a un pasado de Chile, un tiempo que coincidió con la niñez del director: “Estos objetos, que podrían haber sido los mismos que había en mi casa, me recuerdan ese punto lejano cuando uno cree que deja de ser niño" (04:38-49). El autor recurre a este escenario familiar, en el doble sentido de la palabra, para re-orientar al espectador hacia, o hacer accesible para éste, su acercamiento a la memoria de Chile desde la Gran Historia. Al igual que el telescopio, la cámara del documentalista chileno se vale del primer plano lento para poner entre paréntesis estos objetos y tornarlos en dispositivos que orientan temporal (el pasado pre-dictatorial) y espacialmente (Chile) la narración fílmica. La pasión por la astronomía con la que se inicia el filme se sitúa como elemento inherente de la memoria de un pasado que se materializa en una casa familiar "típica" chilena que podría ser la del autor, si bien no lo es. Por ello, los objetos que componen esta casa no se tornan en el anclaje de la memoria individual del director, sino en la memoria colectiva de Chile que es a su vez parte de la memoria de las estrellas.

La crítica ha analizado la materialización de la memoria en objetos como un rasgo distintivo de la obra documental de Guzmán. En Mapping Memory: Visuality, Affect, and Embodied Politics in the Americas (2019), Kaitlin Murphy argumenta que sin objetos las historias memorialisticas carecerían de inmediacidad, "would lack the same level of poignancy and irrefutability, because objects imbue stories with a sense of tangible immediacy" (68). Los objetos, al encarnar vidas e historias pasadas, tienen un carácter performativo del que se vale el documentalista chileno, según Murphy, con el fin de visibilizar la presencia del pasado en el presente y así preservar la memoria (67). Coincido con Murphy en que Guzmán confiere a los objetos un estatus didáctico. En tanto a anclaje de la memoria de un pasado predictatorial, los objetos de esta casa "familiar" buscan generar reflexión acerca 
de la orientación afectivo-política del espectador. El axis de esta maniobra es la meta-narratividad de la metalepsis, articulada en base del dispositivo fílmico que Malin Walhberg acuña como "frame-breaking events," es decir, eventos que rompen el encuadre/marco. El marco, según explica Walhberg en Documentary Time: Film and Phenomenology (2008), se entiende como una presuposición socio-cultural que gobierna nuestra lectura y reacción hacia una situación determinada (50). Los "frame-breaking events" son aquellos entre la audiencia (una risa inesperada) o dentro del espectáculo (una toma larga sin carga dramática) que provocan que el espectador reflexione sobre la situación, historia o imagen (52).

En esta secuencia de la casa familiar el efecto reflexivo se logra gracias al funcionamiento del primer plano lento a modo de un "frame-breaking event." Como plantea Michael Chanan en The Politics of Documentary (2007), el primer plano lento dota de trascendencia al fenómeno bajo observación y así proporciona, "the impression of seeing things as we've never seen them before" (97). El rastreo fenomenológico de Guzmán recurre a este dispositivo fílmico para tornar en extraños, en hacer que "veamos por primera vez," objetos domésticos. Para Ahmed, esta clase de objetos son precisamente históricos porque tradicionalmente son obviados, es decir, quedan fuera de nuestro enfoque debido a que nuestra excesiva familiaridad con ellos hace que olvidemos la historia que encierran (164). Al enmarcar estos objetos mediante la mirada de asombro que evoca el primer plano lento, Guzmán da visibilidad a esta historia, haciendo que éstos se repleten de "vida." Por ponerlo en términos de Ahmed, el primer plano lento de objetos cotidianos provoca que "lo familiar baile de vida": "[wonder directed at the objects we face] allows the familiar to dance with life again" (164). Esta mirada de asombro trae consigo una re-orientación temporal. El filme intenta simular la temporalidad de esta constelación de memoria espacializada vía una especie de montaje poético que "despierta," o hace "bailar de vida," la traza histórica 
que albergan objetos cotidianos. El primer plano lento no se encadena en base a la linealidad del causa-efecto de la continuidad narrativa clásica, sino a través de un ritmo y tiempo fílmico no progresivo dramáticamente. De similar manera al discurso poético, Nostalgia presenta una sucesión temporal de imágenes cuyo principio organizativo es el paralelismo metafórico entre objetos que performan historias pasadas. Esto deriva en un lenguaje poético con carácter meta-narrativo que alienta la interpretación del espectador para que reconozca la importancia del pasado reciente (el Chile pre-dictatorial) y el distante (la materia de las estrellas) en su presente cotidiano.

No es casual que una casa antigua que, según Guzmán podría ser la de su infancia, se convierta en el "punto cero" de la orientación de su memoria encarnada. La casa familiar es, a fin de cuentas, un dispositivo orientador: el espacio que habita y orienta al director. Este dispositivo orientador "domestica" la desorientación que provoca la secuencia inicial de imágenes de astros al romper el marco antropocéntrico, las expectativas temáticas, del documental social. La casa familiar se sitúa como metonimia de la nación para ligar la historia del mundo natural con la historia reciente de la nación chilena de manera accesible para el espectador. Pero en este espacio también se materializa la memoria y con ello, una interacción entre objetos y cuerpos que marca una temporalidad. Estos objetos son portavoces del potencial revolucionario que albergaba el pasado pre-dictatorial, condensado en la metáfora del niño a punto de convertirse en adolescente. En la siguiente escena, hay una transición de la imagen frontal de la casa de la infancia a imágenes de estrellas a través de una "tormenta" de partículas blancas. La voz en off refuerza la metafórica asociación entre tormenta, adolescencia y revolución al referirse al gobierno de Allende: “Un viento revolucionario nos lanzó al centro del mundo. Yo tuve la suerte de vivir esa aventura noble que nos despertó a todos. Esa ilusión quedó grabada para siempre en mi alma" (06:20-34). La narración prosigue para situar esta temporalidad como una 
fallida; como una pérdida provocada por la dictadura de Pinochet: "Más tarde, un golpe de Estado barrió con la democracia, los sueños y la ciencia. A pesar de vivir en un campo de ruinas, los astrónomos chilenos continuaron trabajando con el apoyo de sus colegas extranjeros" (07:22-40). Aunque esta temporalidad se haya quebrado, las ruinas de este proyecto revolucionario siguen formando parte de nuestro presente cotidiano, como denota la memoria que albergan los objetos domésticos al ser mirados con asombro.

En otras palabras, la mirada nostálgica a la casa familiar no se entiende aquí como un ritual melancólico vaciado de potencial político transformador. Nostalgia no se suma a la melancolía pasiva que viene caracterizando el discurso derrotista de la izquierda tras el colapso de la Unión Soviética en 1989 y el posterior apogeo del modelo político-económico neoliberal. ${ }^{3}$ La mirada de asombro, el primer plano lento que "hace bailar de vida" la traza histórica de los objetos domésticos donde se materializa la memoria del Chile pre-dictatorial, se aproxima más bien a la "dialéctica de la derrota" que Enzo Traverso rastrea en una vertiente del comunismo del siglo XX. El crítico italiano desentierra en el pensamiento de Walter Benjamin dos acercamientos contrapuestos a la melancolía: por un lado, la melancolía pasiva, cínica y acrítica en la que se basa el tiempo homogéneo, lineal y vacío del historicismo; por el otro, la melancolía crítica como epistemología alternativa. Traverso asocia esta última con la dialéctica de la derrota comunista, postulando esta melancolía comunista benjaminiana como "historical and allegorical insight into both society and history that tries to grasp the origins of their sorrow and collects the images and objects of the past waiting for redemption" (48). Siguiendo la melancolía comunista benjaminiana, el documental apuesta por un tiempo de narración histórica que "haga bailar de vida”, redima, la traza histórica de objetos domésticos, en lugar del historicismo que los desecha o relega a telón de fondo vaciado de significado. La metalepsis provocada por el primer plano lento, y reforzada por un montaje poético ajeno a la temporalidad lineal 
del historicismo, nos enseña a ver, orienta nuestra mirada hacia, la memoria del mundo doméstico de la casa familiar. En la traza histórica de objetos domésticos se materializa la memoria encarnada de un pasado pre-dictatorial chileno que está a punto de transformarse radicalmente con el ascenso al poder de Allende. En breve, Nostalgia se abre con un retorno a un proyecto político pasado fallido que no ha desaparecido. Esta mirada telescópica al mundo doméstico nos revela que las trazas de este pasado están presentes en nuestro foro más íntimo y cotidiano.

\section{"Gran libro abierto de la memoria:" Atacama como cronotopo}

La crítica al tiempo lineal, homogéneo y vacío del historicismo se condensa en la nueva dirección de los discursos de la memoria que propone Nostalgia en base al planteamiento historiográfico de la Gran Historia. Guzmán desorienta el documental social para re-orientarlo hacia el desierto de Atacama. El filme no relega la naturaleza a telón de fondo, o siguiendo los postulados de Ahmed, no obvia la historia que encierra. En lugar de ello, la voz en off, al compás de planos lentos, nos presenta este espacio natural como "el gran libro abierto de la memoria," es decir, como sinécdoque de la historia cosmos. Todos los elementos de la mise-en-scène (la máquina de coser, las estrellas o los entrevistados) albergan una memoria y un componente alegórico como traza de otra traza histórica. Sin embargo, el "gran museo" que captura todas estas dimensiones materiales y temporales es el desierto de Atacama. Si la casa familiar de la infancia es el "punto de partida" que guía la reconstrucción del pasado político de la nación chilena, el desierto de Atacama es el gran dispositivo orientador que modela una narración histórica unificada (la historia del ser humano, la tierra y el universo). De ahí, la posibilidad de entender el desierto de Atacama como cronotopo artístico. Basándose en la teoría de la relatividad, Mijaíl Bajtín teoriza el cronotopo literario como el discurrir del tiempo condensado en un espacio: "la unión de los elementos espaciales y 
temporales en un todo inteligible y concreto" (2).

No es de extrañar que Guzmán torne en gran dispositivo orientador o en cronotopo artístico este desierto. Atacama es el paradigma de consiliencia de la Gran Historia. El dinamismo de este espacio viene dado por su interacción eterna con el tiempo, o en palabras de Guzmán, por ser un desierto sin una gota de humedad que, "está Ileno de historia." Su particular geografía pone a nuestro alcance elementos de pasados distantes: desde imágenes de los pastores precolombinos grabadas en las piedras hasta los meteoritos que dice albergar bajo las rocas, pasando por hospedar los telescopios más grandes del mundo. Pero su ubicación también lo convierte en testigo de las atrocidades del pasado cercano de Chile. En Atacama yacen, entre otros, un cementerio de trabajadores del mercado capitalista "vertiginoso" del salitre del siglo XIX; o Chacabuco, el campo de concentración más grande durante el régimen dictatorial de Pinochet. Es por ello que en este desierto se unen arqueología, astronomía y memoria histórica. En Atacama, confluyen la cámara del director con las miradas inquisitivas de, entre otros, el astrónomo Gaspar, el arqueólogo Lautaro y Victoria o Violeta, mujeres que buscan los restos de sus familiares asesinados por Pinochet.

La cartografía de este "gran libro abierto de la memoria" se teje metanarrativamente a través de las reflexiones de carácter pedagógico de quienes habitan, de una u otra forma, este espacio. La propia voz-en-off del directornarrador introduce la primera gran lección que nos brinda Atacama: "Aquí, más que ninguna otra parte, yo tengo la impresión que el desierto nos revela un secreto" (17:29-37). Seguido, el astrónomo Gaspar declara que, desde un punto de vista físico, el presente es "una línea muy delgada." Debido a una ínfima distancia entre la luz y el espacio, siempre habrá un desfase temporal entre la imagen del mundo y nuestro momento de percibirla, es decir, una especie de "nostalgia" provocada por la luz. De ahí la gran paradoja del tiempo y el "secreto" del título del documental, homónimo del libro del astrofísico y 
poeta francés Michel Cassé. Lo que percibimos como presente no es más que un reflejo nostálgico. En este sentido, coincido con Tamara Lea Spira en su lectura del tratamiento de la metáfora de la luz en el documental en "Toward a New Temporality and Archive of Revolution: Patricio Guzmán's Nostalgia for/of the Light" (2012). Esta metáfora, tal y como explica Spira, condensa la fragilidad del marco temporal presente, "light, which allows an experience of the 'present' is hence inherently nostalgic, just as we are left nostalgic for a past that is always fleeting" (n.p.). El presente no es más que la nostalgia de la luz que lo que proyecta. Por ello, tal y como expone Guzmán en una entrevista, el presente carece de sentido si no se entiende su interacción con el pasado que lo constituye: "It's a film about the past, a demonstration that the most important thing in life is the past, because the whole territory of the past is fundamental for people and the future" (Guzmán en Darke). Este filme sobre la memoria centrado en Atacama pone en evidencia la gran paradoja del tiempo al revelar la centralidad de, e interconexión entre, todos los pasados. El cineasta chileno prosigue en la entrevista aclarando esta mirada a la memoria histórica desde la Gran Historia: “In as much as we are human beings, we are the inheritors of generation upon generation going back to pre-history, and the matter of our bodies is the matter of the stars. We belong to the Milky Way-that's our home, not just the Earth" (Guzmán en Darke).

Aún así, no todas estas memorias son intercambiables. Al equiparar la orientación hacia el pasado de los astrónomos, arqueólogos y documentalistas con la de Victoria o Violeta salta a la vista que la memoria traumática encarnada de estas mujeres es infinitamente más dolorosa que la de los científicos. Sin embargo, tal y como reitera el astrónomo Gaspar, es la búsqueda de estas mujeres la que la sociedad amnésica de Chile necesita revalorizar. La unificación de las memorias cercanas y distantes que cohabitan Atacama ilumina, por tanto, las carencias de la narración histórica oficial chilena. Según explican el director-narrador y el arqueólogo Lautaro, el país se vuelca en el estudio 
del pasado más lejano, mientras que el golpe de Estado bloquea el proyecto de memoria histórica: "Es una paradoja. El pasado más cercano a nosotros lo tenemos encapsulado; es una paradoja enorme... Nuestras historias más cercanas las hemos mantenido en un nivel de ocultamiento" (26:24-27:18). Atacama, no obstante, es una constelación de la memoria que revela la fragilidad del presente al visibilizar alegóricamente las trazas históricas que la visión lineal, patriótica y progresista de la "Historia" intenta ocultar. Este "gran libro abierto de la memoria” nos enseña, además, a vislumbrar en estas trazas (el cementerio, los meteoritos, los dibujos de las rocas...) la interacción entre ser humano y su entorno físico. La melancolía activa de los supervivientes de la dictadura, del mismo modo que la de los astrónomos o arqueólogos, se dirige críticamente hacia las trazas históricas que preserva el desierto con el fin de entender el presente y extraer lecciones para el futuro.

A nivel fílmico, el propio documental performa esta concepción temporal del presente. En la anterior sección, discutía que la narración histórica alternativa que propone Nostalgia se organiza en base a una temporalidad no-lineal, basada en la asociación metafórica o en el montaje poético. La conceptualización fílmica de Atacama como cronotopo refuerza la temporalidad de simultaneidad de este montaje poético. Atacama no encaja con los cronotopos clásicos del documental—el viaje o el ciclo de una medida del paso del tiempo exterior como el día o el año. El cronotopo de Guzmán se mueve en un tiempo verbal más en línea con el "presente perfecto." Según la gramática, el "presente perfecto" es un tiempo verbal que expresa cómo el pasado sigue entrometiéndose en el presente y que condiciona a éste, destapando la interacción y simbiosis entre ambos marcos temporales. Atacama es la imagen del pasado por la que se mueven en el presente los arqueólogos, pero también, como explica Lautaro, la coordenada desde donde los astrónomos se orientan en base a imágenes de un pasado más distante. Al conectar estas reflexiones meta-narrativas de los entrevistados con el 
paralelismo entre la cámara y el telescopio se intensifica esta metalepsis. Con la ayuda del cronotopo de Atacama, esta metalepsis nos alienta a ver la temporalidad de la imagen en movimiento que el cine, como máquina del tiempo, esconde. Al igual que un astrónomo, el espectador de Nostalgia estará analizando imágenes del pasado como inherentes al momento presente para dar sentido a lo que está viendo en ese instante.

La función metaléptica y pedagógica del paralelismo entre cámara y telescopio se hace evidente en la escena final: "Yo creo que la memoria tiene fuerza de gravedad, siempre nos atrae. Los que tienen memoria son capaces de vivir en el frágil tiempo presente. Los que no la tienen no viven en ninguna parte. Cada noche, lentamente, impasible, el centro de la galaxia pasa por el cielo de Santiago" (1:27:12-52). Esta apelación de la voz en off al espectador cierra el documental con una panorámica circular que registra desde las alturas el Santiago de Chile nocturno. El narrador-director resume así el enunciado que plantea Nostalgia: la Gran Historia dirige nuestra mirada hacia la memoria, la traza histórica, que alberga nuestro frágil presente para orientarnos temporalmente hacia un "presente perfecto." La conducta ejemplar que sugiere el cineasta es, entonces, aquella que ponen en práctica todos los entrevistados en el documental al esbozar un presente sustentado en una mirada retrospectiva. Pero también la propia conducta de Guzmán: el enunciado de Nostalgia es de carácter performativo para éste. Al lanzar una mirada al pasado pre-dictatorial de Chile (su niñez), el director explora cómo esta orientación perdida determina su forma de entender el presente político. Este enunciado performativo será redoblado al alcanzar a su receptor por la paradoja temporal inherente al medio cinematográfico.

\section{El marco heteropatriarcal: La memoria como herencia familiar}

Nostalgia es un filme preocupado por, aparentemente, todo tipo de interconexiones (lo individual y lo colectivo, la ciencia y el arte, lo social y lo 
natural, pasado y presente...) y por cómo estas colocan en nuestro alcance elementos que el tiempo lineal, homogéneo y vacío de la narración histórica oficial relega a telón de fondo (la naturaleza, el mundo doméstico y lo personal). Es por ello sorprendente la falta de atención a las intersecciones identitarias que orientan la propia manera de habitar el mundo del director. El documental comienza anclando la visión del narrador-director del pasado en la casa familiar, pero obvia cualquier tipo de reflexión sobre cómo este dispositivo orientador media su propia mirada a la memoria. Guzmán desafía la visión historicista al traer a primer plano la memoria encarnada de un Chile pre-dictatorial a punto de transformarse políticamente, la cual se materializa en la traza de objetos domésticos. Sin embargo, ni esta memoria ni la orientación que marcan son neutros. La mirada de asombro que dirige a estos objetos relega al fuera de campo parte de la historicidad que su cotidianidad encierra. La repetición de la familia heteropatriarcal, esta orientación, se materializa en los objetos del hogar para "ponerles sexo" y al mismo tiempo, borrar la traza histórica de esta labor. Según explica Ahmed, la repetición provoca que experimentemos las orientaciones como originarias: "[orientations] can operate simultaneously as effects and be lived or experienced as if they are originary or a matter of how one's body inhabits the world" (Queer Phenomenology 80). A la hora de recrear la posible casa de la infancia del director, Nostalgia cae en esta experimentación de la familia heteropatriarcal como lo originario, lo familiar. Al compás de la voz en off del director-narrador, los planos de objetos sexuados pincelan al resto de la familia "típica" chilena de los años 70 . La división de trabajo de la nación patriarcal capitalista ayuda a trazar estos retratos: una máquina de coser se convierte en sinécdoque de la madre, mientras que una radio antigua y un primer plano de una silla nos evoca la figura del padre. Las mesas para reuniones familiares y el cuadro de La última cena terminan de consagrar, de dar cohesión, a esta "típica" familia chilena católica. En breve, la memoria que este montaje poético nos incita a rescatar vía la melancolía activa tiene sexo y sexualidad. 
Esta exposición de objetos domésticos enmascara una historia de organización sexual del mundo doméstico y forma de la familia (la pareja heterosexual).

El director-narrador no cuestiona este marco, la dirección heteropatriarcal, que performa la casa familiar de la infancia y junto con ello, el "punto cero" de la re-orientación hacia la memoria del filme. El obviar esta posición limita de varias maneras su "novedoso" acercamiento a la memoria desde la Gran Historia. En primer lugar, Nostalgia podría desarrollar un acercamiento más riguroso a la memoria de la naturaleza si no omitiera la labor social que hace que ésta sea legible para el ser humano. Es decir, el filme relega al fuera de campo la imposibilidad de acceder a la historia del mundo natural sin la mediación de lo social. Pero en este ensayo, mi preocupación recae en las implicaciones de esta omisión en lo que concierne a los discursos de la memoria de la dictadura de Pinochet. El marco heteropatriarcal del documental reitera el tradicional reconocimiento del sujeto histórico, el que hace y el que escribe historia, como masculino heterosexual. Con ello, termina reproduciendo la operativa de poder de la nación heteropatriarcal. Pese a ser obviado o reducido a telón de fondo, este posicionamiento no deja de ser político y tiene dos consecuencias principales interrelacionadas: por un lado, el filme confina al sujeto femenino al ámbito de lo familiar y, por otro, la trasmisión de la memoria se enmarca en la retórica de reproducibilidad heterosexual.

La melancolía comunista benjaminiana que revaloriza el filme poco tiene de equitativa. La división del trabajo de la nación patriarcal capitalista que evoca la secuencia inicial del hogar se extiende al exterior. En Nostalgia, el mundo de la ciencia parece ser exclusivo al sujeto masculino, tal y como sugiere el género de todos los expertos científicos que comparten el conocimiento de su disciplina. El documental articula una oposición jerárquica sexuada entre el conocimiento de la memoria distante que valora la nación chilena (la arqueología, la astronomía ...) y la memoria encarnada de un pasado reciente. Esta oposición jerárquica se podría interpretar como una crítica de la nación patriarcal capitalista que 
equiparase el tratamiento del género femenino con el de la memoria histórica. No obstante, pese a condenar el tradicional fuera de campo del sexuado mundo doméstico y la naturaleza en la historia oficial, Guzmán no cuestiona las propias relaciones de poder que constituyen estos campos ni la relación de éstos con la historia. En lugar de fijar el foco en los procesos histórico-políticos que sexualizan la división del trabajo capitalista, las entrevistas a mujeres en el documental reiteran el binario sexuado razón-ámbito político (masculino) versus emoción-ámbito de lo privado (femenino). El filme codifica la mujer y su memoria en clave de un duelo sexuado, de una labor afectiva "femenina", hacia un sujeto masculino político. La memoria encarnada de Violeta y Vicky adquiere estatus histórico únicamente en función de la lucha política del sujeto masculino desaparecido hacia quien se dirige el duelo.

El propio trato del escenario en el que se presentan estas entrevistadas refuerza esta concepción. Nostalgia explota la tradicional asociación del género femenino con la naturaleza de manera que el duelo de estas mujeres sature de emoción el paisaje en el que se materializa la memoria: el desierto de Atacama. En "Archival Landscapes and a Non-Anthropocentric Universe Memory in Nostalgia de la luz/Nostalgia for the Light (2010)," David Martin-Jones nota el paralelismo entre la cara de angustia envejecida de Violeta y la orografía del paisaje que le sirve de fondo. Para Martin-Jones, el efecto de esta analogía es la personificación, el poner cara y afecto, a la traza histórica de la memoria reciente de Chile que encierra el desierto: “Berríos's story appears as though spoken by the landscape precisely because Berríos has physically become a part of the landscape through her repetitive actions in that space" (720). En la primera sección de este ensayo, argumentaba que el montaje fotogénico de la segunda secuencia enfatiza la mirada de asombro telescópica, el primer plano lento, a los objetos doméstico para hacer "bailar de vida" su traza histórica. La cara de angustia femenina donde se visibiliza el duelo produce el mismo efecto en los elementos naturales que comprende Atacama. No es mi 
intención sugerir que el duelo de estas mujeres debe ser relegado a telón de fondo, sino cuestionar la manera en que esta labor afectiva se codifica como femenina fílmicamente vis-a-vis el sujeto científico y político masculino. En Nostalgia, quien inscribe esta labor afectiva en la historia, al igual que quien escribe la memoria del universo o la de la pre-historia, es el sujeto masculino. Quien eleva el duelo de estas mujeres a rango histórico y redime la lucha del sujeto político masculino represaliado no es otro que el cineasta.

Este marco heteropatriarcal no es exclusivo a Nostalgia, sino más bien una limitación histórica de la izquierda y su melancolía activa benjaminiana. Según advierte Carl Fischer en Queering the Chilean Way: Cultures of Exceptionalism and Sexual Dissidence, 1965-2015 (2016), las afirmaciones masculinistas imperan en las obras nostálgicas de la izquierda chilena: "the masculinist assumptions underlying the utopian visions of equality and socialism in nostalgic artistic works created after the fall of the UP can be easily identified" (9). Para Fischer, son pocos los artefactos culturales memorialísticos sobre el periodo de la dictadura que se han centrado en los disidentes sexuales que se sienten excluidos de las narrativas de duelo de la izquierda (185). El documental de Guzmán no es uno de ellos. El interés interdisciplinario del cineasta pasa por alto planteamientos interseccionales de la memoria histórica chilena como el de Pedro Lemebel. Pese a la negativa de la izquierda chilena, Lemebel, reconocido artista y activista queer, insiste en emparejar las muertes de represaliados políticos con las provocadas por el sida durante la dictadura (Fischer 200). Nostalgia, al igual que la izquierda que critica el proyecto alternativo de Lemebel, deja fuera de encuadre la memoria de resistencia de todos aquellos sujetos que no se ciñen al sujeto político tradicional de la izquierda (masculino y heterosexual). El filme excluye la historia de formas políticas alternativas de oposición a la dictadura, como la disidencia sexual.

No obstante, la casa familiar va más allá de establecer la memoria de un pasado pre-dictatorial como un punto cero sexuado, o una forma de acercarse 
al mundo y a la memoria de éste desde el marco heteropatriarcal de la nación capitalista. Este marco no solo dicta quién es digno de hacer y escribir memoria histórica, sino cómo se trasmite la memoria encarnada de un pasado reciente de la nación. La narración histórica alternativa que propone Nostalgia comienza en la casa familiar. Esto posiciona como punto de partida la herencia familiar y, metonímicamente, la de la nación. Como espacio sexuado, la casa familiar impone una herencia basada en la retórica de reproductibilidad heterosexual de la nación capitalista. La reconceptualización de Ahmed de la herencia es útil para esclarecer este punto. En “Mixed Orientations” (2014), Ahmed repiensa la herencia familiar heterosexual como el obsequio de ciertos objetos materiales y creencias que nos orientan hacia ese mismo ideal de familia (99). La herencia familiar pone a nuestro alcance una serie de objetos que fijan una orientación sexual. Estos objetos demandan que devolvamos ese obsequio reproduciendo la misma forma de familia. Bajo esta retórica de reproductibilidad, la futuridad de la nación recae en el receptor de esta herencia, el niño. El tropo que guía la apertura de la narración histórica de Guzmán revela cómo ésta se estructura en base a la heteronormatividad. El niño que, como discutía anteriormente, está a punto de despertar alude metonímicamente a la nación chilena dando paso a la revolución.

La escena de la entrevista a Valentina, hija de desaparecidos y astrónoma para el Observatorio Europeo Austral, une la feminización del duelo del filme con el planteamiento heteropatriarcal de transmisión de la memoria encarnada. A diferencia de su colega Gaspar, el conocimiento de Valentina viene acompañado de su labor afectiva como, según la voz en off del directornarrador, casada y madre de dos hijos. La astrónoma reflexiona sobre cómo heredó de sus abuelos la memoria de los ideales políticos de sus padres, quienes el régimen de Pinochet hizo desparecer cuando ella apenas tenía un año. La voz diegética de Valentina pasa a voz en off cuando el documental, siguiendo los postulados de la Gran Historia, intercala primeros planos de ella 
con imágenes de sus abuelos reposando en el sofá de la casa, de las estrellas o fotografías de sus padres. Guzmán se vale de nuevo del efecto metaléptico del primer plano lento para retratar el paso del tiempo en el rostro de los abuelos. Esta metalepsis alienta al espectador a ver la memoria de un proyecto político alternativo fallido como herencia familiar y de la nación. Las últimas imágenes de la escena, Valentina con su bebé en brazos, refuerzan esta trasmisión heteropatriarcal de la memoria al conceptualizarla como proceso vertical que sigue las líneas temporales del árbol genealógico.

En definitiva, Nostalgia performa una narración unificada de la historia que instrumentaliza las interconexiones entre las trazas históricas de los elementos que comprende el cosmos. Con ello, el documental revela la fragilidad del presente e invita al espectador, a través de la metalepsis, a reorientarse espacial y temporalmente. La obra rompe, por tanto, el marco antropocéntrico e historicista (tiempo lineal, homogéneo y vacío) de la historia oficial para plantear una "nueva" dirección de la memoria histórica. No obstante, deja intacto el marco del punto cero, la casa familiar, desde el que se articula su fenomenológica aproximación a la memoria del cosmos: la familia heteropatriarcal. La mirada fílmica de asombro que dirige Guzmán a la traza histórica de los elementos del cosmos performa, y simultáneamente enmascara, la historicidad de la división de trabajo de la nación patriarcal capitalista y su retórica de reproductibilidad. Nostalgia sigue el patrón heteropatriarcal que históricamente ha orientado los discursos de la memoria de la izquierda. El sujeto masculino heterosexual es el único sujeto histórico reconocido. Es además la memoria encarnada de su lucha política la que se trasmite dentro de la familia heterosexual. A fin de cuentas, pese a las pretensiones universalistas de la sentencia final de Guzmán, "los que no viven en ninguna parte” de la constelación de memoria del documental son quienes no encajan en ese guion heteropatriarcal. Lo que una lectura de Nostalgia desde la fenomenología queer feminista de Ahmed desvela son los riesgos de formular la memoria 
histórica como una cuestión de recordar u olvidar. El reto de las sociedades posdictatoriales del siglo XXI no recae simplemente en "tener memoria" para "vivir en el frágil tiempo presente," sino en cómo esa memoria que se reclama performa una historia de relaciones de poder que oculta otras memorias.

\section{Notas}

1 Para estudios anteriores sobre la Gran Historia, véase Christian (2011).

2 Para una crítica del tratamiento de Nostalgia del paisaje como imagen-archivo donde se deposita una memoria no-antropocéntrica, véase Martin-Jones. Para un estudio del documental como parte de un movimiento eco-cosmopolita transnacional, véase Parham y Marland. Para una lectura crítica de los discursos de lo global en la obra documental de Guzmán desde el concepto de "etnoplanetariedad" (ethnoplanetarity), véase Radisoglou. Para un estudio sobre el desarrollo del pensamiento "ecológico" de Guzmán en El botón de nácar (2015), véase Hollweg.

3 Para una teorización de la melancolía derrotista de la izquierda, véase Brown. Para un estudio sobre la relación entre el neoliberalismo y la memoria en Chile, véase Fernando Blanco.

4 Para una aproximación teórica al cronotopo del género documental, véase Chanan (2007).

5 Para un estudio del binario sexuado duelo-melancolía y la devaluación de los ritos de duelo femeninos, véase Schiesari.

6 Estas observaciones son fruto de conversaciones con Cecilia Enjuto Rangel y Mariko Plescia.

\section{Obras citadas}

Ahmed, Sara. "Mixed Orientations." Subjectivity, vol. 7, no. 1, 2014, pp. 92-109.

-. Queer Phenomenology: Orientations, Objects, Others. Duke UP, 2006.

-. "Orientations: Toward a Queer Phenomenology." GLB, vol. 12, no. 4, 2006, pp. 543-574.

Bakhtin, Mijail, y Helena S. Kriúkova. Teoría y estética de la novela: Trabajos de investigación. Taurus, 1989. 
Benjamin, Walter. On the Concept of History. Createspace Independent Publishing Platform, 2016.

Benjamin, Craig, Esther Quaedackers, and David Baker. The Routledge Companion to Big History. Routledge, 2018.

Blaine, Patrick. "Representing Absences in the Postdictatorial Documentary Cinema of Patricio Guzmán.” Latin American Perspectives, vol. 40, no. 1, 2013, pp. 114-130.

Blanco, Fernando. Neoliberal Bonds: Undoing Memory in Chilean Art and Literature. Ohio State UP, 2015.

Brown, Wendy. "Resisting Left Melancholy.” Boundary 2, vol. 26, no. 3, 1999, pp. 1927.

Cassé, Michel. Nostalgie de la lumière: Monts et merveilles de l'astrophysique. Belfond, 1988.

Chanan, Michael. "Nostalgia de la luz." La Fuga, 2012, www.lafuga.cl/nostalgia-deluz/586. Fecha de acceso: 24 jul. 2020.

—. The Politics of Documentary. British Film Institute, 2007.

Christian, David. Maps of Time: An Introduction to Big History. U of California P, 2011.

Fischer, Carl. Queering the Chilean Way: Cultures of Exceptionalism and Sexual Dissidence, 1965-2015. Palgrave Macmillan, 2016.

Guzmán, Patricio, director. Nostalgia de la luz. Icarus Films Home, 2010.

—. Salvador Allende: A Film. Icarus Films, 2004.

—. El caso Pinochet. Barcelona: Paco Poch \& Benecé Documental, 2001.

—. Chile, la memoria obstinada. Icarus films, 1997.

—. El Botón de nácar. Atacama Productions, 2015.

—. La cordillera de los sueños. Atacama Productions, 2019.

-. Entrevistado por Chris Darke. "Nostalgia for the Light: Interview." PBS - POV: Documentaries with a Point of View, 2012, archive.pov.org/nostalgiaforthelight/ interview/. Fecha de acceso: sep. 2020.

-. Entrevistado por Nerina Moris. "Nostalgia for the Light." Vertigo, vol. 31, 2012, www.closeupfilmcentre.com/vertigo_magazine/issue-31-winter-2012-inconversation/nostalgia-for-the-light/. Fecha de acceso: sep. 2020. 
Hollweg, Brenda. “A Questioning Situation: Patricio Guzmán’s Cine-essayistic Explorations of Fragile Planetary Configurations." New Cinemas: Journal of Contemporary Film, vol. 15, no. 1, 2017, pp. 13-32.

Martin-Jones, David. "Archival Landscapes and a Non-Anthropocentric 'Universe Memory' in Nostalgia de la luz/Nostalgia for the Light (2010).” Third Text, vol. 27, no. 6,2013 , pp. 707-722.

Murphy, Kaitlin M. Mapping Memory: Visuality, Affect, and Embodied Politics in the Americas. Fordham UP, 2019.

Parham, John, y Marland, Pippa. "Every Night the Universe Passes over Santiago: Transnational 'Ecocinema' and Visualising Environmental Histories in Patricio Guzmán's Nostalgia for the Light." White Rabbit: English Studies in Latin America, no. 12, December 2016.

Radisoglou, Alexis. "Ethnoplanetarity: Contemporaneity and Scale in Patricio Guzmán's Nostalgia de la luz and El botón de nácar.” Other Globes Past and Peripheral Imaginations of Globalization, editado por Simon Ferdinand, Irene Villaescusa-Illán y Esther Peeren, Palgrave-MacMillan, 2019, pp. 195-211.

Schiesari, Juliana. The Gendering of Melancholia: Feminism, Psychoanalysis, and the Symbolics of Loss in Renaissance Literature. Cornell UP, 1992.

Spira, Tamara Lea. "Toward a New Temporality and Archive of 'Revolution:' Patricio Guzmán's Nostalgia for/of the Light." emisférica, vol. 9, no. 1, 2012, hemisphericinstitute.org/en/emisferica-91/9-1-review-essays/oward-a-newtemporality-and-archive-of-revolution-patricio-guzmans-nostalgia-for-the-light. html. Fecha de acceso: 24 jul. 2020.

Traverso, Enzo. Left-wing Melancholia: Marxism, History, and Memory. Columbia UP, 2017.

Valenzuela, Valeria. "Yo te digo que el mundo es así: Giro performativo en el documental chileno contemporáneo." vol. 1, 2006, doc.ubi.pt/01/artigo valeria valenzuela.pdf. Fecha de acceso: 24 jul. 2020.

Vitullo, Julieta. "Nostalgia de la luz de Patricio Guzmán: El cine como máquina del tiempo." Kamchatka Revista de Análisis Cultural, 2014, pp. 179-192.

Wahlberg, Malin. Documentary Time: Film and Phenomenology. U of Minnesota P, 2008. 